\section{EDUCACIÓN PARA LA CONVIVENCIA INTERCULTURAL}

\author{
Dimitrinka G. Níkleva \\ Departamento de Didáctica de la Lengua y la Literatura \\ Facultad de Ciencias de la Educación \\ Campus Universitario de Cartuja, s/n \\ 18071 Granada (España) \\ nikleva@ugr.es
}

\begin{abstract}
This paper focuses on the necessity of developing the affective intercultural communicative competence to encourage intercultural coexistence, which is so distinctive of our current society. It presents a brief review of some basic terminology related to the subject and it outlines some difficulties for the intercultural coexistence.

Within the educational context, the treatment of the multicultural issues in the classroom provides diverse opportunities to solve this type of intercultural conflicts: teaching values, using conflict as a learning resource and preventing.

The present study delves into the cultural stereotypes that exist in the Spanish society, as well as their linguistic representations. This paper tries to collaborate in the formation of positive attitudes towards cultural diversity. At the end, it offers a didactic proposal for the application of the theme dealt with in this article to the class of Spanish Language and Literature.
\end{abstract}

KEY WORDS: interculturalism; affective competence; cultural stereotypes; Spanish Language and Literature class.

\section{INTRODUCCIÓN}

La realidad multicultural de la sociedad actual presenta un abanico de ventajas junto con una serie de problemas que requieren una política orientada al tratamiento de estos aspectos en todos los contextos institucionales. Dentro de estos contextos, el ámbito educativo sin duda tiene gran importancia, debido a que es alli donde se crean las personas y su sistema de valores.

En nuestra experiencia en el nivel de la Educación Secundaria Obligatoria hemos observado que la participación en clase de los alumnos inmigrantes se restringe, porque los alumnos de origen español mantienen el orden existente, refuerzan la asimetría y las relaciones de poder. Por todo ello, los docentes somos conscientes de que la escuela debe colaborar en la creación de esta sociedad multicultural y

\section{EDUCATION FOR INTERCULTURAL COEXISTENCE}

RESUMEN: El artículo se centra en la necesidad de desarrollar la competencia comunicativa intercultural afectiva para conseguir la convivencia intercultural tan característica de nuestra sociedad actual. Presenta un breve repaso de alguna terminología básica relacionada con el tema y esboza algunas dificultades para la convivencia intercultural. En el ámbito educativo, el tratamiento de los temas multiculturales en el aula aporta distintas oportunidades para resolver este tipo de conflictos interculturales: educar en valores, usar el conflicto como aprendizaje y prevenir.

El presente estudio profundiza en los estereotipos culturales que existen en la sociedad española y en su expresión lingüistica. El objetivo es colaborar en la formación de actitudes positivas hacia la diversidad cultural.

Al final, ofrece una propuesta didáctica para la aplicación del tema estudiado a la clase de Lengua castellana y Literatura en la etapa de la Educación Secundaria Obligatoria.

PALABRAS CLAVE: interculturalidad; competencia afectiva; estereotipos culturales; clase de Lengua.

en la formación de actitudes positivas hacia la diversidad cultural. Pero solo el hecho de conocer algunas diferencias culturales entre los hablantes de distintas lenguas o entre distintas etnias no es suficiente para hablar de interculturalidad. Podemos hacerlo cuando se establecen relaciones no discriminatorias, basadas en el respeto y la tolerancia. Dicho brevemente, el objetivo es la convivencia. Se trata de superar la actitud pasiva de aceptación de la diferencia y conseguir la comprensión del Otro. Además, todo esto nos aportaría un enriquecimiento cultural. Resumiendo, la interculturalidad implica diálogo, comprensión y encuentro.

En este estudio nos planteamos destacar la convivencia como condición imprescindible de nuestra sociedad, esbozar los problemas, profundizando en los estereotipos culturales $y$, al final, ofrecer una propuesta didáctica para llevarla a cabo en la clase de Lengua. 


\section{BASE TERMINOLÓGICA}

Como punto de partida conviene precisar los significados de los términos clave, aunque no abarquemos la gran variedad de matices que recibe su uso por parte de distintos autores.

Según Giménez Romero (2004), hay que distinguir entre el plano fáctico (de los hechos) y el plano normativo (de las propuestas sociopolíticas y éticas). En el plano fáctico sitúa la multiculturalidad (diversidad cultural, lingüística, religiosa, etc.) y la interculturalidad (relaciones interétnicas, interlingüísticas, interreligiosas, etc.). En el plano normativo incluye el multiculturalismo (reconocimiento de la diferencia) y el interculturalismo (convivencia en la diversidad). Todos estos fenómenos son modalidades del pluralismo cultural.

Vilà Baños (2007) señala cinco áreas del estudio intercultural: la comunicación intercultural, internacional, interracial, interétnica o minoritaria, y contracultural. Obviamente, estas áreas se centran en la comunicación entre personas de distintos referentes culturales, distintos países, razas, etnias y, por último, la comunicación contracultural se inserta en procesos de desarrollo y colonización.

Se puede diferenciar también entre comunicación transcultural (entre distintos modelos comunicativos) y comunicación intracultural (dentro de una misma etnia). Como ejemplos de comunicación intracultural señalaríamos la comunicación de género, la comunicación de clase social, la comunicación rural-urbana, la comunicación regional y la comunicación de cultura organizacional.

\section{LA COMPETENCIA AFECTIVA: UNA PREMISA PARA LA CONVIVENCIA MULTICULTURAL}

Queremos destacar este tipo de competencia por la importancia que tiene para hacer posible el diálogo inter- 0 multicultural y la convivencia.

La competencia afectiva consiste en la capacidad de proyectar y recibir respuestas emocionales positivas en las interacciones personales. En el caso de una comunicación intercultural, se trataría de una sensibilidad intercultural, cuyos componentes serian: la empatía, la actitud de no juzgar al otro, la motivación para la comunicación intercultural, el control de la ansiedad, etc. (ibíd.)

\section{Los estereotipos CUlturales COMO OBStáculo PARA LA CONVIVENCIA}

Los estereotipos son una forma de clasificar o encasillar a la gente, de poner una etiqueta a un grupo de personas a veces $\sin$ conocer ni siquiera a un representante de este grupo. Sin duda son inexactos. Lo que solemos hacer es adoptar la imagen que nos dan los medios de comunicación. Lo importante es que a cada estereotipo se asocia un juicio de valor que está en la selección misma de imágenes y símbolos, entre todos los posibles, para representar al grupo estereotipado. Existen estereotipos de nacionalidades, razas, clases, grupos, sexos, ocupaciones, etc. En nuestro ámbito -el educativo- como en todos los demás ámbitos de la sociedad, existen prejuicios hacia los inmigrantes que dificultan la convivencia.

Para conocer mejor estos estereotipos, vamos a repasar alguna definición, sus funciones, principios de construcción y tipos.

Una definición de estereotipo sería: "modelo o idea simplificada y comúnmente admitida de algo" (M. ${ }^{\text {a Moliner, }}$ Diccionario de uso del español).

La etimología de la palabra estereotipo es otro dato de interés. El origen del término remite al siglo XVIII. Surgió en el ambiente tipográfico para indicar la reproducción de imágenes impresas por medio de formas fijas. La palabra proviene del griego: stereós ("sólido, rígido") y typos ("carácter, tipo o modelo") (Cano Gestoso, 1993).

Se usó por primera vez fuera de este medio en el ámbito psiquiátrico y se refería a comportamientos patológicos caracterizados por la obsesiva repetición de palabras y gestos. Walter Lippmann, un periodista, fue quien introdujo el término en las ciencias sociales en 1922 con un libro que publicó sobre los procesos de formación de la opinión pública. El autor considera que la relación cognoscitiva con la realidad externa se realiza a través de las imágenes mentales que nos hacemos de esa realidad y, por 
consiguiente, está fuertemente influida por la prensa, que en aquella época empezaba a adquirir las connotaciones modernas de la comunicación de masas. Según Lippmann, esas imágenes mentales ("pictures in our heads") son a menudo simplificaciones burdas y casi siempre muy rígidas (es decir, estereotipos), porque la mente humana no es capaz de comprender la infinita variedad y complejidad del mundo (Mazzara, 1999; Sangrador García, 1981). Así que se procede a una simplificación de la realidad que no es arbitraria ni individual, sino que se construye sobre la base de cánones establecidos culturalmente.

\section{LAS FUNCIONES DE LOS ESTEREOTIPOS}

Mencionaremos brevemente las funciones de los estereotipos, porque son las que explican las razones de su existencia y su mecanismo. Nos basamos en la clasificación de funciones de Sangrador García (1981), quien las reúne en cuatro grupos.

\subsection{Proyección y desplazamiento}

Se trata de dos mecanismos defensivos del yo. El primero -la proyección- consiste en proyectar en otros grupos aquellos deseos y sentimientos que se consideran inaceptables socialmente. El otro mecanismo defensivo -el desplazamiento- se explica con las frustraciones de las personas. Normalmente, estas frustraciones generan agresividad que se va acumulando hasta que las personas necesiten descargarla y terminan por desplazarla hacia un grupo minoritario que sirve de "chivo expiatorio". Así surgen los estereotipos como manifestación de esta actitud hostil y agresividad desplazada. El desplazamiento se relaciona con la teoría del chivo expiatorio (conocida también como "cabeza de turco"). Chivo expiatorio es aquel que carga con la culpa que, de no ser así, caería sobre nosotros.

\subsection{Justificación de actitudes o conductas hacia el grupo estereotipado}

Ya hemos visto que los estereotipos sirven para justificar actitudes y conductas hostiles y pueden provenir de un desplazamiento o de un conflicto intergrupal real. Una consecuencia importante es que de esta manera consiguen mantener la estructura social existente. Un estereotipo negativo de un grupo minoritario o marginado sirve como justificación para negarle la igualdad de oportunidades, ciertos bienes, etc. Si a los miembros de este grupo se les considera "perezosos", parecerá "normal" que no se les dé trabajo; si son "poco inteligentes", no merece la pena que estudien. En esto se basan las llamadas "profecías autocumplidas": una desigualdad de trato genera una desigualdad real con el tiempo (ibíd.). Dicho de otra manera, en el caso de los estereotipos, la causa y el efecto aparecen a la inversa. Por ejemplo, si el desempleo es la causa y la ociosidad es su efecto y por ello estamos observando a jóvenes sin trabajo vagando por las calles, con el tiempo se crea el estereotipo de que los jóvenes son perezosos (causa) y por eso están en el paro (efecto). Esta inversión de las relaciones de causa y efecto en el análisis de la realidad social es una manera de desviar la culpa. Es decir, no se pensaría que el problema es el desempleo y es responsabilidad de los grupos de poder.

Otro ejemplo de discriminación relacionado con la teoría del chivo expiatorio puede ser el de un grupo étnico estereotipado como muy trabajador. En la situación de una crisis económica y aumento del paro mucha gente pierde su trabajo y reacciona emocionalmente, echándole la culpa al grupo trabajador estereotipado.

Hemos de precisar también que no se crean estereotipos de todos los grupos de la sociedad. Por ejemplo, no hay estereotipos sobre los conductores de autobús. Pero sí existen estereotipos sobre los funcionarios, los jóvenes irresponsables, los gitanos, las rubias, los empollones, entre muchos otros.

Estereotipamos sobre grupos que de alguna manera representan un problema, una amenaza o una molestia para la sociedad que deseamos tener. Pueden estar relacionados con la amenaza de guerra o con la amenaza a la posición privilegiada de los grupos dominantes en una comunidad. En conclusión, los estereotipos reflejan las relaciones de poder dentro de la sociedad.

Por último, hay que advertir que los estereotipos no son eternos. Son difíciles de cambiar, pero no son invariables. Los estereotipos de los diferentes grupos se van modificando con los cambios de la sociedad. 


\subsection{Economía cognitiva y predictibilidad de conducta}

Es una doble función que fue formulada por los autores de línea cognitiva. Estos autores se centran no en las connotaciones despectivas que normalmente tienen los estereotipos, sino en aspectos positivos como su utilidad para facilitar la comunicación al simplificar las complejidades del entorno. Los estereotipos forman parte de un proceso de categorización que capacita al individuo para predecir lo que le rodea. De este modo, actúan como una especie de modelo y nos proporcionan un alto grado de ahorro tanto de esfuerzo analítico como de tiempo. Por ejemplo, si nos encontramos con un miembro del grupo estereotipado, tendemos a pensar que él poseerá los rasgos básicos del estereotipo y esta suposición se convierte en el punto de arranque para la interacción.

Los autores que han establecido esta doble función concluyen que reaccionar ante cada persona y cada acontecimiento como si fuera una identidad única no es posible ni conveniente.

Por otra parte, queremos recordar que los estereotipos no son los únicos que ofrecen esa economía cognitiva y predictibilidad de conductas. Tienen las mismas funciones también los gestos, el color de la piel, el modo de vestir, los registros de la lengua, etc. Es decir, el lenguaje verbal y no verbal, los aspectos sociolingüisticos y culturales nos proporcionan el mismo tipo de información.

\subsection{Identificación social del individuo e integración grupal}

Según esta función, los individuos se perciben a sí mismos como miembros de ciertos grupos, dentro de los cuales algunas actitudes son aceptadas de un modo más o menos oficial. El individuo se identifica con ellas en su deseo de ser aceptado por el grupo. Por ejemplo, la integración de un individuo en grupos políticos, religiosos, etc., requiere la aceptación por su parte de los estereotipos predominantes en este grupo, especialmente de los referidos a otros grupos políticos o religiosos.

Recordemos que los grupos hacia los cuales son mantenidos estereotipos pueden modificar su propia conducta como resultado de ello. Así, un estereotipo que tal vez fuese falso en sus orígenes termina por ser verdadero. Es decir, el grupo estereotipado, debido a la imagen que se tiene de él, puede llegar a comportarse de modo consecuente con esta imagen.

\section{LOS PRINCIPIOS DE CONSTRUCCIÓN DE LOS ESTEREOTIPOS}

Los dos principios fundamentales que participan en la creación de los estereotipos son el universalismo y el relativismo.

¿Existen valores universales o los valores son relativos? Este debate ha tenido un amplio eco en la historia del pensamiento y ha sido el tema de investigación de Tsvetan Todorov en su libro Nosotros y los otros (2007), de donde hemos recogido algunas ideas al respecto.

El etnocentrismo (o egocentrismo) define lo "verdadero" mediante "lo nuestro", identifica nuestros valores con los valores. Dicho de otra forma, representa una versión del universalismo.

Según el otro principio de construcción de los estereotipos -el relativismo-, todo valor está determinado espacial y temporalmente. Por consiguiente, hay que renunciar al universalismo ilusorio y mantener las tradiciones nacionales y regionales. El relativista no emite juicios sobre los otros.

¿Cómo resolver entonces el conflicto entre lo universal y lo particular? A lo largo de la historia se ha visto que la ideología universalista es la máscara del etnocentrismo. Es la responsable de las conquistas coloniales, realizadas bajo el pretexto de extender "la civilización" (entendida como valor universal). Ya es hora de olvidar las pretensiones universales y de reconocer que todos los juicios son relativos: a una época, a un lugar, a un contexto. El bien de hoy no es el de ayer. Como señala Todorov $(2007,433)$, el individuo "hace muy bien la corrección por cuenta propia, y no confunde el amor con la justicia: ama a su hijo más que al del vecino, pero cuando ambos se encuentran en su casa les da partes iguales del pastel".

Hay que reconocer también que el relativismo no es la solución milagrosa de los problemas que nos ocupan aquí. 
Por ejemplo, el relativista no puede denunciar ninguna injusticia, ni violencia, por temor a que estas formen parte de una tradición distinta a la suya: ni los sacrificios humanos, ni la ablación del clítoris, etc. pueden ser reprobados.

Quizá la solución sea un nuevo humanismo, un humanismo crítico.

Otro punto importante que queremos destacar es que la diferencia entre animales y hombres está en la ausencia o la presencia no de razón, sino de libertad. Esto es lo relevante: la libertad del hombre, su capacidad para transformarse. Por lo cual destaca la importancia de la educación -el ámbito que nos incumbe a los docentes-.

\section{TIPOS DE ESTEREOTIPOS: AUTOESTEREOTIPOS Y HETEROESTEREOTIPOS}

Hay que diferenciar entre estos dos tipos: auto- y heteroestereotipos. Los autoestereotipos representan la imagen que un pueblo tiene de sí mismo y esta imagen tiende a ser favorable. Al contrario, los heteroestereotipos son la imagen que los demás tienen sobre un pueblo y suelen ser desfavorables, lo que demuestra un cierto etnocentrismo.

En cuanto a los españoles, algunos de sus autoestereotipos más divulgados señalan la siesta como el deporte nacional; los toros, como la fiesta nacional y la envidia, como el vicio nacional. Hay que añadir también los autoestereotipos de: alegría, fiesta y diversión. Además, podemos decir que los españoles comparten los hetereostereotipos de los demás sobre ellos: sol y playa. ¡Y no olvidemos el jamón!

Hemos puntualizado que, al contrario, los heteroestereotipos corresponden a la imagen que los demás tienen sobre los españoles.

\section{Propuesta didáctica para la clase de Lengua CASTELLANA Y LiterATURA}

No cabe duda de que la lengua es el principal medio de comunicación y está cargada de los valores dominantes de una cultura. Después de conocer los estereotipos y los problemas que conllevan para la convivencia multicultural, nos proponemos introducirlos en la clase de Lengua en la E.S.O para comentarlos y destruirlos después de una reflexión basada en materiales adecuados. Nos parece adecuado también insertar este aspecto dentro del tratamiento de los temas transversales en el currículo de Lengua. La educación intercultural se integraría dentro de la Educación para la Paz.

En el Apéndice hemos recopilado material adecuado para trabajar este tema: se trata de una amplia muestra de unidades fraseológicas con gentilicios y topónimos. La mayoría de ellas encierra actitudes estereotipadas y podemos utilizarlas en nuestras clases.

\section{PROPUESTA DIDÁCTICA}

\section{Título de la actividad:}

Nosotros y los otros

\section{Justificación de la actividad}

Esta actividad tiene como objetivo básico el de desarroIlar la competencia comunicativa intercultural afectiva. Contribuye a iniciarse en el control de actitudes negativas que dificultan la comunicación multicultural y desarrollar la empatía y los elementos afectivos.

\section{Objetivos}

- Iniciarse en el control y la superación de algunas emociones y actitudes negativas.

- Desarrollar actitudes positivas y la empatía.

- Desarrollar el interés por la comunicación multicultural.

Descripción de la actividad

La actividad consiste en conocer y reflexionar sobre los estereotipos en español reflejados en la fraseología con gentilicios y topónimos.

\section{Número de sesiones: 2 .}

\section{Materiales}

1. La lista de fraseologismos con gentilicios y topónimos elaborada por el profesor (Apéndice). 
2. Ejemplos de estereotipos sobre los españoles.

a) Una muestra variada:

- Fiesta, sol, playa, jamón, toros;

- los andaluces son vagos;

- los catalanes son tacaños;

- los españoles son bajos y morenos;

- los españoles hablan muy alto y son ruidosos;

- hablan simultáneamente;

- son acogedores;

- no son puntuales;

- la manera de conversar de los españoles tiene que ver con la idea de que "el diálogo es un monólogo intercalado".

b) Estereotipos portugueses sobre los españoles.

Aquí cabe precisar que estos estereotipos fueron recogidos durante una estancia en Lisboa en la Facultad de Letras en 2008.

- habla como un español (cuando un niño todavía no habla bien; todavía no ha aprendido portugués);

- un pueblo español (caos, desorden);

- hablar inglés como una vaca española, francés (hablar muy mal inglés); otra variante: hablar inglés como una cabra española, francés;

- los españoles compran con los dedos; o alguien mira las cosas como si fuera español;

(Significa que "mira tocando", es decir, toca las cosas en sitios donde no deberia hacerlo. Según los portugueses, los españoles tocan los artículos en las tiendas más de la cuenta).

\section{- madrina a la española;}

Eso quiere decir que la madrina se convierte en amante del novio. Lo mismo viene a significar padrino a la española: padrino y amante de la novia.

Terminemos con un refrán portugués: De España ni buen viento, ni buen casamiento. El origen del refrán tuvo que ver con los casamientos reales.

\section{Metodología}

\section{Sesión 1}

1. Terminar las oraciones que se dan a continuación añadiendo los tres adjetivos más representativos (10 minutos):

Los ingleses son ....

Los alemanes son

Los rusos son

Los japoneses son

Los chinos son

Los andaluces son

Los catalanes son

Los eslavos son

Los gitanos son

(Observación: El docente puede reducir o ampliar la actividad añadiendo naciones, minorias étnicas, etc.)

2. Elaborar una lista con fraseología en español que contenga gentilicios y topónimos (20 minutos).

3. Comparar con la lista que ofrece el profesor (10 minutos).

4. Buscar en las dos listas (la del alumno y la del profesor) los fraseologismos que expresan estereotipos, xenofobia o racismo (10 minutos).

5. Reflexionar y comentar su opinión sobre estos estereotipos (10 minutos).

\section{Deberes}

Hacer una redacción y relacionar con los temas de multiculturalidad reflexionando sobre la siguiente frase de Tsvetan Todorov: [el individuo] "no confunde el amor con la justicia: ama a su hijo más que al del vecino, pero cuando ambos se encuentran en su casa les da partes iguales del pastel".

\section{Sesión 2}

1. Recordar el tema de la sesión anterior y debatir oralmente sobre los estereotipos conocidos sobre los es- 
pañoles (la opinión de los demás sobre los españoles). Consultar los ejemplos recogidos en los materiales (10 minutos).

2. Leer y comentar algunas de las redacciones (los deberes) (40 minutos).

3. Formular oralmente conclusiones de las dos sesiones (10 minutos).

\section{Orientaciones para la evaluación}

Valorar el cambio de emociones y actitudes, el grado de empatía, la madurez de las conclusiones, la interacción con los demás (alumnos y profesor) durante las clases.

\section{Productos de evaluación}

La redacción, el debate oral, las conclusiones formuladas.

\section{Conclusiones}

La multiculturalidad conlleva una serie de ventajas enriquecedoras a la vez que un amplio abanico de problemas y conflictos en todos los sectores de nuestra sociedad.

En el ámbito educativo, el tratamiento de los temas multiculturales en el aula nos aporta distintas oportunidades para resolver este tipo de conflictos: educar en valores, usar el conflicto como aprendizaje y prevenir.

En este estudio nos hemos centrado en los estereotipos, por representar una simplificación burda y una distorsión injusta de la realidad. Su aceptación inconsciente se debe a dos factores: la falta de pensamiento crítico y la falta de conocimiento. Por ello el profesorado tiene un papel fundamental en la formación del alumnado en general y en el desarrollo de su competencia intercultural afectiva, en particular. De ahí, la importancia de que sea consciente de este papel, de que por su parte tenga la formación necesaria y la actitud imprescindible para poner en marcha una intervención pedagógica en esta línea. Nuestra propuesta didáctica ha sido puesta en marcha con alumnos de distintos niveles y ha obtenido siempre magníficos resultados: incita a reflexionar, a conversar, contar experiencias propias, ser crítico, replantearse los valores y las actitudes, produciendo cambios en ellos al desarrollar la empatía. Paralelamente, desarrolla la comunicación oral y escrita. La principal ventaja que permite estos resultados es que el tema resulta muy ameno para los alumnos y estos se implican con mucho interés en todas las actividades.

Por otra parte, el conocimiento de los otros es una vía hacia el conocimiento de uno mismo. Es el término necesario de comparación. $Y$ por lo tanto, es un elemento enriquecedor.

No olvidemos que la realidad que vivimos en el aula responde a una construcción social y, por lo tanto, un proyecto de educación multicultural dependerá de la transformación del cuadro sociopolítico.

\section{APÉNDICE}

\section{LISTA DE UNIDADES FRASEOLÓGICAS CON GENTILICIOS Y TOPÓNIMOS}

\author{
A mi plin, que soy de Lalín. \\ Arder Troya. \\ Beber como un cosaco. \\ Boca española no habla sola. \\ ¡Buen punto filipino! \\ Cabeza de turco. \\ De Aragón, ni hembra ni varón. \\ De Madrid al cielo. \\ Despedirse a la francesa (o marchar a la francesa). \\ En Adra, el que no muerde, ladra. \\ Engañar como a un chino. \\ Entre Pinto y Valdemoro. \\ Estar en la Babia. \\ Estar más chupado que la pipa de un indio. \\ Guay del Paraguay. \\ Hablando del rey de Roma, por la puerta asoma. \\ Hablar en cristiano. \\ Hacer el indio. \\ Hacer el martirio chino. \\ Hacer las Américas. \\ Hacer una judiada. \\ Hacerse el sueco (no te hagas el sueco). \\ Hay (o no hay) moros en la costa.
}


Inglés pirata es.

Ir (salir) de Guatemala a Guatepeor. (Ir de mal en peor).

Ir de la Ceca a la Meca.

Ir en fila india.

Irse por los cerros de Úbeda.

Justicia catalana.

Los catalanes de las piedras hacen panes.

Los últimos de Filipinas.

Malafollá granaína.

Más se perdió en Cuba.

Naranjas de la China.

París bien vale una misa.

Pasar una noche toledana.

Poner una pica en Flandes.

Ponerse flamenco.

Quedarse a la luna de Valencia.

Quien fue a Sevilla perdió su silla; quien vino de Gijón se la quitó.

Quien tiene un tío en Graná ni tiene tío ni tiene na.

Respuesta gallega.

Revolver Roma con Santiago.
Salga el sol por Antequera (y póngase por donde quiera / y la luna por donde quiera).

Salir de Málaga y entrar en Malagón.

Salir por los cerros de Úbeda.

Ser la obra de El Escorial.

Ser un gitano.

Ser un húngaro.

Ser un judio.

Ser un mongol.

Ser un moro.

Ser un lujo asiático.

Ser un trabajo de chinos.

Ser un vándalo.

Tener más trampas que una película de chinos.

Todos a una como en Fuenteovejuna.

Todos los caminos conducen a Roma.

Tomar las de Villadiego.

Trabajar como un chino.

Trabajar como un negro.

Valer un Potosí.

Zamora no se ganó en una hora.

\section{BIBLIOGRAFÍA}

Álvarez Montalbán, F. (2007): Hacerse el sueco. Estereotipos culturales en el lenguaje popular español. En http:// www.archivo-chileensuecia.se/docs/ Hacerse\%20el\%20sueco.pdf.

Antón, M. (2010): "Aportaciones de la teoría sociocultural al estudio de la adquisición del español como segunda lengua", en RESLA (Revista Española de Lingüística Aplicada), 23, 9-30.

Castillo Carballo, M. ${ }^{\text {a }}$ A. (2002): "Conocimiento cultural en la adquisición de la L2: la fraseología", ASELE. Actas XIII. En http://cvc.cervantes.es/ensenanza/ biblioteca_ele/asele/pdf/13/13_0209. pdf.

Cano Gestoso, J. I. (1993): Los estereotipos sociales: el proceso de perpetuación a través de la memoria selectiva, Madrid, Universidad Complutense de Madrid.
Ciapuscio, G. y Kesselheim, W. (1997): "Usted, ¿qué es?: Categorizaciones y contexto institucional", en K. Zimmermann y C. Bierbach (eds.), Lenguaje y comunicación intercultural en el mundo hispánico (105-130), Frankfurt am Main, Vervuert Verlag. Madrid, Iberoamericana.

Lippmann, W. (1956 [1922]): Public Opinion, New York, McMillan.

Mackie, M. M. (1973): "Arriving at truth by definition: Case of stereotype innacuracy", Social Problems, 20, 431-447.

Maestro Backsbacka, F. J. (2000): "Las relaciones de comercio y navegación entre Suecia-Noruega y España en el siglo XIX". En A. Ramos Santana (coord.), Comercio y navegación entre España y Suecia (siglos X-XX) (pp. 365-456). Cádiz, Servicio de Publicaciones de la Universidad de Cádiz.
Recibido: 30 de septiembre de 2010 Aceptado: 29 de septiembre de 2011 
Mazzara, B. M. (1999): Estereotipos y prejuicios, Madrid, Acento.

Moliner, M. (2001): Diccionario de uso del español, Madrid, Gredos.

Quin, R, y McMahon, B. (1997): Historias yestereotipos, Madrid, Ediciones de la Torre.

Ramiro Roca, E. (2005): "¿Murcianos y gente de bien?", RED (Revista de Educación a Distancia), 5, 13. En http:// www.um.es/ead/red/13.
Sangrador Garcia, J. L. (1981): Estereotipos de las nacionalidades y regiones de España, Madrid, Centro de Investigaciones Sociológicas.

Serradell, O., Munté, A. (2010): "Dialogicidad y poder en el discurso racista y antirracista", en Revista Signos, 43 (número especial, monográfico n. ${ }^{\circ}$ 2), 343-362.

Soler-Espiauba, D. (1999): "Gitanos, murcianos y demás gente de mal vivir... con pelos y señales. Los idiomatismos en la clase de E/LE", Carabela, 45, 47-62.

Todorov, T. (2007): Nosotros y los otros. Reflexión sobre la diversidad humana, Madrid, Siglo veintiuno editores.

Vinacke, W. E. (1956): "Explorations in the dinamic process of stereotyping", Journal of Social Psychology, 43, 211214. 